Supporting Information

\title{
Hierarchical surface architecture of plants as an inspiration for biomimetic fog collectors
}

\author{
M. A. K. Azad, ${ }^{\gamma^{*}}$ W. Barthlott ${ }^{\dagger}$ and K. Koch ${ }^{*}$
}

'Nees Institute for Biodiversity of Plants, Rheinische Friedrich-Wilhelms-University of Bonn. Venusbergweg 22, 53115, Bonn, Germany

${ }^{\ddagger}$ Faculty of Life Sciences, Rhine-Waal University of Applied Sciences. Marie-Curie Straße 1, 47533, Kleve, Germany

*Corresponding author: Md. Abul Kalam Azad, E-mail: azad@uni-bonn.de 


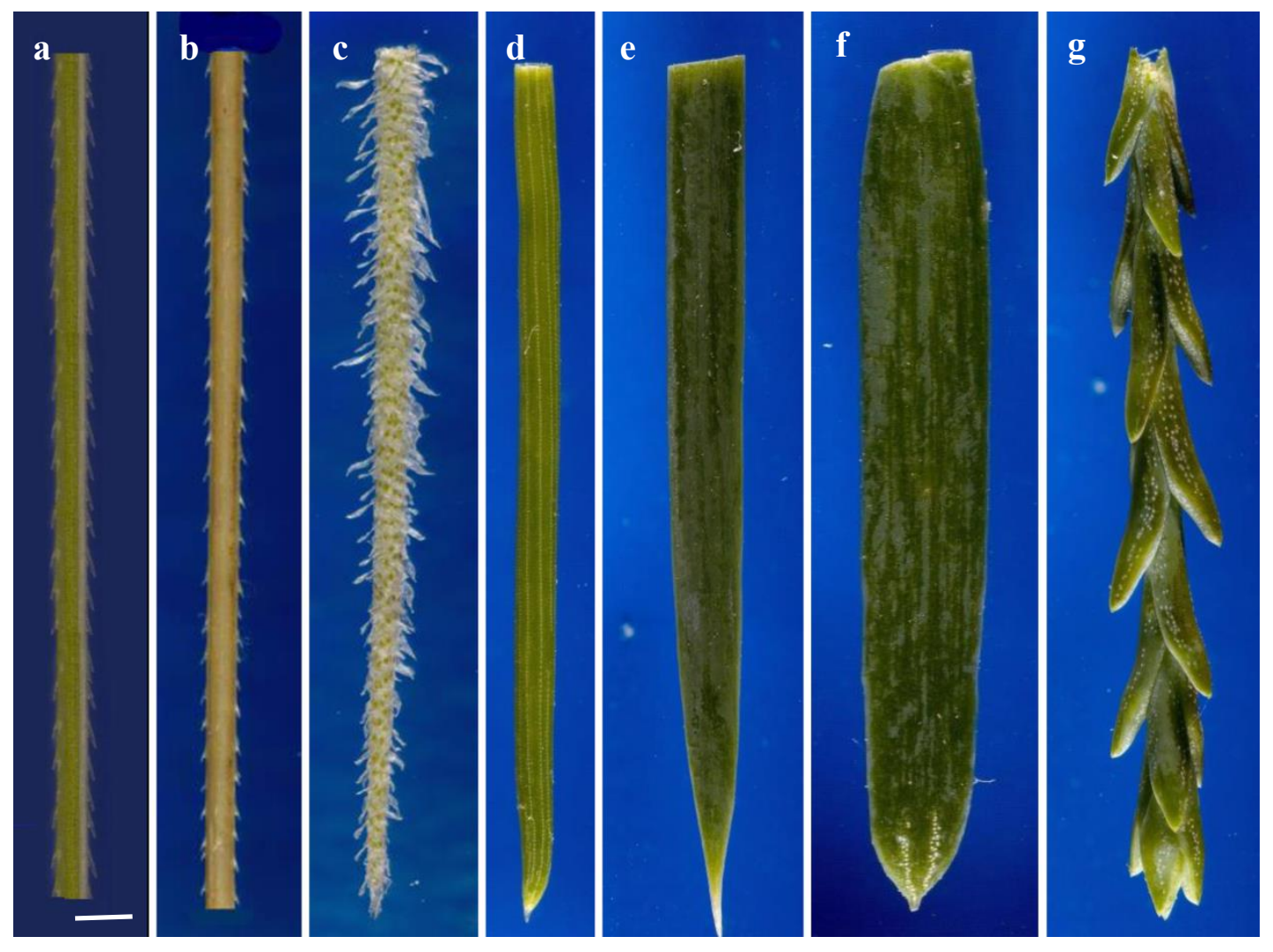

Figure S1: Awns/needles/needle like structures used in the fog collection experiment; (a) a fresh and (b) a DH awn of Hordeum vulgare, (c) a leaf of Tillandsia usneoides and needles of (d) Pinus canariensis, (e) Abies bracteata, (f) Sequoia sempervirens and (g) Sequoiadendron giganteum. Scale bar $1 \mathrm{~mm}$. 


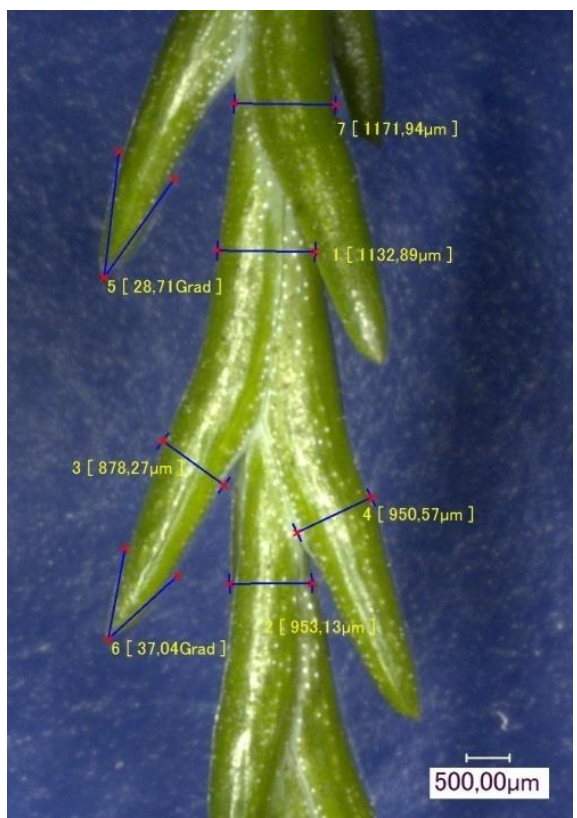

Figure S2: Structural characteristics of a needle of Sequoiadendron giganteum. Cone like structures of varying dimensions are attached to the main axis of the needle. The needle was oriented with the tip and cone like structures directed downwards as this is the mainly found orientation on the trees.

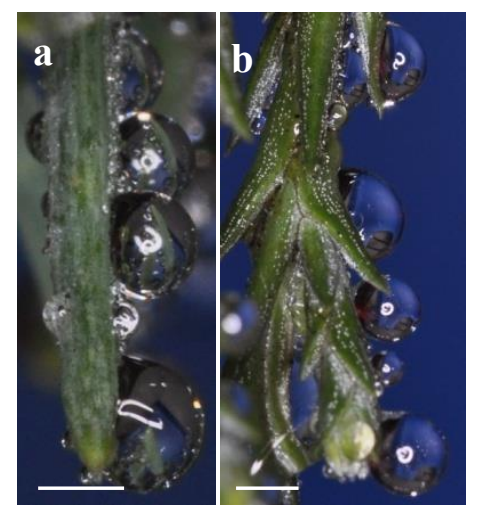

Figure S3: Fog droplet behavior on the surfaces of the needles of (a) Pinus canariensis and (b) Sequoiadendron giganteum. Scale bar $1 \mathrm{~mm}$. 

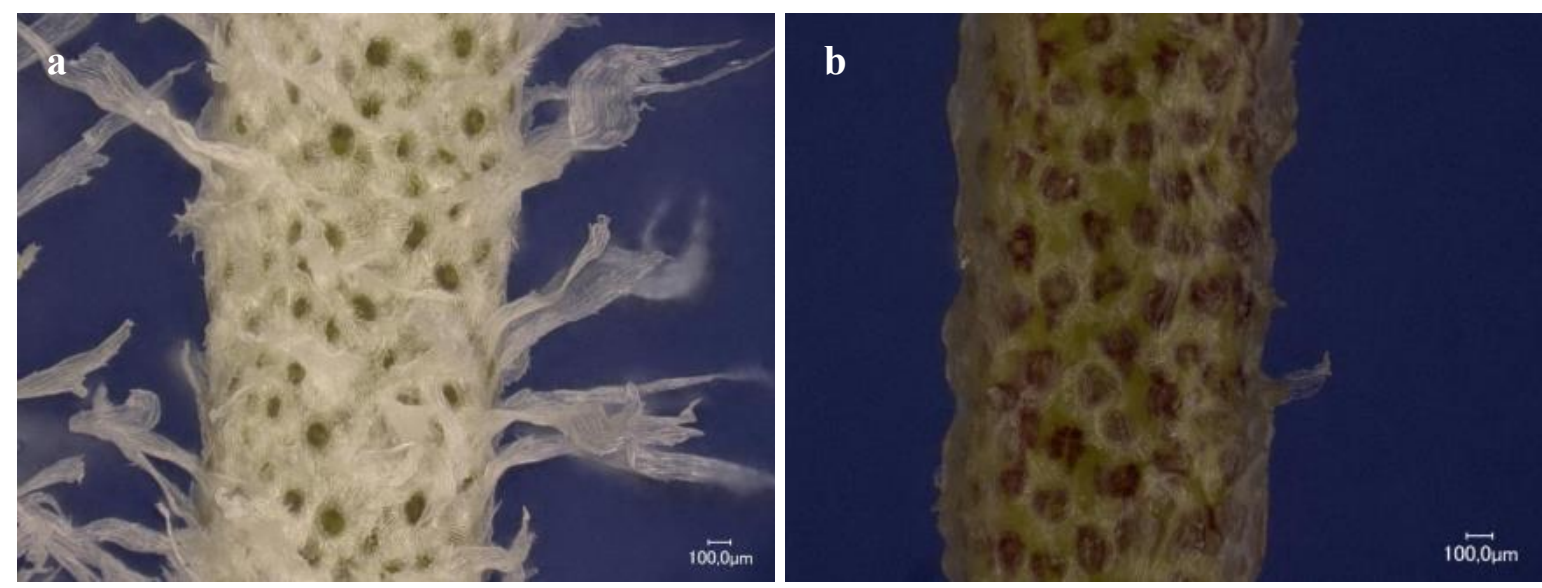

Figure S4: (a) A dry leaf of Tillandsia usneoides shows trichomes all around it; (b) a wet and saturated leaf after a few minutes of fog collection; no free trichomes are seen. 